\title{
A More Practical Method for Explaining Equilibrium
}

\author{
Yi-Jang $\mathrm{Yu}^{1}$ \\ ${ }^{1}$ Department of Economics, Ming-Chuan University, Taiwan, R. O. C. \\ Correspondence: Yi-Jang Yu, Department of Economics, Ming-Chuan University, 5 Der Ming Road, Gui Shan \\ District, Taoyuan County 333, Taiwan, R. O. C. Tel: 886-3-350-7001 ext. 3241. E-mail: yjyu@mail.mcu.edu.tw
}

Received: February 21, 2014

Accepted: March 3, $2014 \quad$ Online Published: March 4, 2014

doi:10.5430/rwe.v5n1p88

URL: http://dx.doi.org/10.5430/rwe.v5n1p88

\begin{abstract}
The aim of this study is to suggest a more practical method for explaining market equilibrium in a two-dimensional risk-return world. Its main difference from textbook contents is to define, in both qualitative and quantitative ways, the environment or the system factor and treat it as an endogenous variable. Once the two-dimensional framework that is capable of managing uncertainty and environmental relationship can be reasonably established, a greater number of economic issues can be effectively investigated. As to the traditional concept of economic equilibrium, its importance can be significantly reduced.
\end{abstract}

Keywords: equilibrium, environment factor, system factor, uncertainty

\section{Introduction}

As well as scarcity, another important element that is unavoidable in most economic analyses should be uncertainty. Recently, a few scholars specializing in math have proved that, as long as there is uncertainty, market equilibrium can only be a coincidence (Arutyunov, 2013). Under normal circumstances, very few economists dare to challenge their mathematical specialty. However, if more facets other than uncertainty can be explained, there may be hope of earning back their respect.

The first thing that can be immediately explained is that, both scarcity and lavishness can cause economic problems and failures. Another fact is that, no failure, no economic problems.

Next, the job of risk management is already multivariate, including techniques of transfer, diversification, parallel exchange and others. However, even for a well-diversified global enterprise, global economy is still the uncontrollable environment factor which, in turn, is more relatively simplified than the one faced by a localized company. Clearly, quantification is the key to measure precisely the difference between these two different types of environment factor.

In addition, every risk-related job of economic analysis should also compromise the element of time since myopia is never rational, especially when personal life is limited and the nation's life must be perpetual, even personal consumption should also conform to the goal of national sustainment. Otherwise, the right of future generations will be infringed upon, and living conditions of the nation will deteriorate when myopia, at present, already leads to over consumption.

It is well known that the environment factor has long been thought to be immeasurable, and as this is not a result of intuitive negligence, since the capability of its quantification could not be realized until after the birth of Markowitz's portfolio theory. Moreover, since this theory has long been strictly applied in financial markets, its proliferation into economic textbooks takes time.

Finally, from an economic viewpoint, although factors affecting market supply and demand can widely vary, a general framework applicable for both sides must always be applied if and when issues relating to market equilibrium are discussed. While information of demand is difficult to observe, starting with the market side to construct the framework of analysis, and then to extend this framework to link up with the supply side, is thus necessary. Moreover, since there is a time difference of occurrence, the way to bridge the market and the supply side must be to rely on a certain type of behavioral relationship.

Clearly, may more explanations are needed to reveal the actual nature of economic equilibrium. The aim of this study is therefore to suggest a more practical method for explaining market equilibrium in a two-dimensional risk-return 
world. Its main difference from textbook contents is to define, in both qualitative and quantitative ways, the environment or the system factor and treat it as an endogenous variable. Once the two-dimensional framework that is capable of managing uncertainty and environmental relationship can be reasonably established, a greater number of economic issues can be effectively investigated. As to the traditional concept of economic equilibrium, its importance can be significantly reduced.

\section{Uncertainty and Risk}

The simplest way to quantitatively describe an uncertain future price is to explain using the following two contents, all possible prices or a range of prices and all corresponding probabilities of occurrence at the next period. Since individual probability is not directly measurable, an appropriate hypothesis must be borrowed. After many years of scientific studies, while focusing only on human behavior, the currently accepted one is the hypothesis of lognormal distribution (Limpert et al., 2001).

In terms of definition, the original intention behind applying an expected rate of return is to conform to the principle of equality in performance evaluation. As to the reason why standard deviation is usually taken to represent risk, and therefore clearly needs a more detailed explanation. Assume the uncertain price (in the logarithmic form) to be $\widetilde{P}_{1}$ or its rate of change to be $\widetilde{r}_{1}$, the corresponding probability density function to be $f$, the expected value can thus be expressed as $E\left(\widetilde{P}_{1}\right)$ or $E\left(\widetilde{r}_{1}\right)$, respectively. After setting a threshold as $P^{*}$, or an opportunity cost as $r_{f}$, clearly, the loss area is all the possible outcomes inferior to $P^{*}$ or $r_{f}$ covered by the curve representing $f$. As the loss area narrows, the standard deviation of $P^{*}$ or $r_{f}$ also decreases. Therefore, for convenience, standard deviation is taken to represent risk, and the premise is that $P^{*}$ or $r_{f}$ must locate on the left-hand side of $E\left(\widetilde{P}_{1}\right)$ or $E\left(\widetilde{r}_{1}\right)$, respectively.

As long as it is not the case of perfectly elastic or inelastic, based on the assumption of all other things being equal, the principle of demand can become the dominant force to guide market transactions. For example, once demand elasticity drops to the one-hundred percent level and further decreases, the total revenue will also decrease correspondingly. For a company or nation, this certainly means that the possibility of economic failure is on the increase. The driving force of globalization must include these kinds of considerations, because only cutting costs can immediately rescue the rate of return on investment (Yu, 2013a). As for the way of improving the demand condition in the long run, since raising incomes for consumers is hardly a choice by suppliers, the only alternative is therefore to change the consumption preference. This clearly requires innovation in order to regain a higher demand elasticity and to avoid the risk of failure.

\section{Environment Factor and System Factor}

Since sources affecting either $\sigma$ or $E$ can vary significantly, a standard tool is thus required for the job of performance evaluation. Among all different methods of basic calculation, while both $\sigma$ and $E$ have different attributes, only division can be applied to merge them. In statistics, $\sigma / E$ has been defined as the coefficient of variation; in economics, especially in the financial market, $E / \sigma$ can be interpreted as "the expected rate of return that should be obtained by assuming one unit of risk". However, since the opportunity cost can always be obtained without assuming any risk, therefore, only the part of the excess rate of return $E-r_{f}$ that is necessary to be appraised with respect to $\sigma$. Consequentially, $E / \sigma$ needs to be adjusted into $\left(E-r_{f}\right) / \sigma$ which, in turn, coincides with the Sharpe ratio.

However, ordinal Sharpe ratios, especially those negative ones, cannot be easily interpreted (Israelsen, 2005), unless short sales can be allowed (Sharpe, 1994). As to per unit of risk, since the content of, and the ratio between, its systematic and individual components can vary among different assets, they must be heterogeneous and cannot be mutually comparable in the risk world. Intuitively, based on the hypothesis of lognormal distribution, the Sharpe ratio is suggested to be transformed into a measure of cumulated probabilities, $N\left[\left(E-r_{f}\right) / \sigma\right]$, and is called WINDEX (Cheng, 2002). Since the initial slope basis in ordinal sense can now be transformed into the cumulated probability basis in cardinal sense, the job of appraising performance among different assets can now become possible.

By replacing the opportunity cost with a basis of performance evaluation or a target of growth rate, thereby easily applying WINDEX to study a wide range of economic issues within the ' $\sigma-E$ ' framework. For example, if the 
target of economic growth rate can also be set as $r_{f}$, the corresponding WINDEX can then be interpreted as 'the chance of success of achieving the target' and can be applied to find out the optimal allocation of resources for one industry or a nation. When the best development opportunities in the environment can be exactly represented by this optimal allocation of resources, or the so-called market portfolio, what is left is the other environment factor representing restrictions that needs to be resolved.

Even if there is only one single company in an industry, the environment factor with respect to restrictions already can exist but not the system factor which, in turn, can only be effectively represented after the industry can meet the risk diversification condition expressed in Fama (1976). This means, based on Markowitz's portfolio theory, the efficient frontier constituted by the whole industry can by now have reached the degree of significant risk diversification, and its minimum-risk portfolio can represent the system factor of this industry.

Clearly, the environment or even the system factor can always vary with respect to changing time, or places, or matters. For example, for a localized company its environment factors can include areas from geopolitical location to the global economy. But for a well-diversified global enterprise only the global economy can be its environment factor. It is therefore necessary to take the smallest environment to be the definition for the localized company, since this definition already includes within it every related and larger environments.

In addition, studies of ethics are always confronted with an obstacle of not being quantifiable. However, the logic with the concept of risk diversification may provide a clue. For example, in the world of ethics, common ethics can be possibly represented by the systematic component and can be abided by all people. In contrast, private ethics should also be respected in order to produce a significant effect of diversification and to maintain a more stabilized society. By the same token, through preserving more multivariate industries, the whole of society can also reserve more possibilities of incubating major industries in the future.

\section{Two-dimensional Analytical Framework}

In statistics, expected value $E$ is the basis for measuring variance $\sigma^{2}$ or standard deviation $\sigma$, but not the opposite. Therefore, once the analytical environment needs to be expanded from one-dimensional ' $E$ ' into two-dimensional ' $\sigma-E$ ', every related analytical job has to be initiated from the risk dimension of $\sigma^{2}$ or $\sigma$, and then transformed into the return dimension of $E$.

Assuming the growth rate of a certain economic entity is $\widetilde{r}_{i}$, according to the Markowitz concept of risk diversification, the related total risk $\sigma_{i}^{2}$ must be the sum of related nondiversifiable systematic component $\sigma_{T}^{2}$, assuming its existence, plus diversifiable individual component $\sigma_{i d}^{2}$. The problem is, the original variable $\widetilde{r}_{i d}$ for presenting $\sigma_{i d}^{2}$ cannot be directly observed. However, since the following risk relation stands

$$
\sigma_{i}^{2} \equiv \sigma_{T}^{2}+\sigma_{i d}^{2}
$$

its related variable relation can therefore be inferred as

$$
\widetilde{r}_{i} \equiv \widetilde{r}_{T}+\widetilde{r}_{i d}
$$

and this is because $\widetilde{r}_{T}$ and $\widetilde{r}_{i d}$ are not related at all in the risk sense. The unobservable $\widetilde{r}_{i d}$ can thus be inferred through the portfolio of $\widetilde{r}_{i}-\widetilde{r}_{T}$.

Next, since the source of impact and behavioral pattern can all differ for either systematic or individual risk component, it is thus necessary to establish individually the behavioral variable relation between the systematic variable $\widetilde{r}_{T}$ and its related supply-side variable $\widetilde{R}_{T}$ as

$$
\widetilde{r}_{T}=\alpha_{1} \widetilde{R}_{T}+\varepsilon_{T}
$$

and to establish indirectly the behavioral variable relation of the individual factor $\widetilde{r}_{i d}$ and its supply-side representative through eq. (2) as

$$
\widetilde{r}_{i d} \equiv \widetilde{r}_{i}-\widetilde{r}_{T}=\alpha_{2}\left(\widetilde{R}_{i}-\widetilde{R}_{T}\right)+\varepsilon_{i-T}
$$


in which, $\widetilde{R}_{i}-\widetilde{R}_{T}$ is the individual component with supply-side property, is taken by removing $\widetilde{R}_{T}$ from $\widetilde{R}_{i}$ which, in turn, represents the supply-side variable of $\widetilde{r}_{i}$.

After bringing both equations (3) and (4) into (2), the behavioral variable relation between $\widetilde{r}_{i}$ and its supply-side components can thus be established as

$$
\widetilde{r}_{i}=\alpha_{1} \widetilde{R}_{T}+\alpha_{2}\left(\widetilde{R}_{i}-\widetilde{R}_{T}\right)+\left(\varepsilon_{T}+\varepsilon_{i-T}\right)=\left(\alpha_{1}-\alpha_{2}\right) \widetilde{R}_{T}+\alpha_{2} \widetilde{R}_{i}+\varepsilon_{i}
$$

In view of econometrics, once there is a systematic explanatory variable in the bivariate model, the sum of both coefficients can only be 1 , hence $\hat{\alpha}_{1}$ in eq. (5) must also be 1 (Yu, 2012).

However, in contrast to financial assets, non-financial commodities are usually more or less interrelated, (Note 1) and this means there probably exists certain relationships with other commodities, such as substitutes, or complements, or products in strategic alliance, that need to be considered. While all these relationships do not belong to either the controllable part of $\widetilde{r}_{i d}$, or the uncontrollable part of $\widetilde{r}_{T}$, a third variable of $\widetilde{r}_{N}$ is thus needed, and eq. (5) can be modified into

$$
\widetilde{r}_{i}=\beta_{1} \widetilde{R}_{T}+\beta_{2} \widetilde{R}_{N}+\beta_{3} \widetilde{R}_{i}+\varepsilon_{i}
$$

Again, from the point of view of econometrics, the sum of all three coefficients can only be 1 when one of the three explanatory variables is a system factor. Related proof will be provided in [Appendix I].

It can thus be believed that, based on the existence of a strong mechanism of self-control presented in eq. (5) or (6), economic activities should be highly rational in essence. They become chaotic only when the system factor is completely excluded from economic analyses. For example, as has been clearly explained in Yu (2012), since CAPM does not include the right system factor, it would become a runaway horse that is difficult to control. Once the right system factor can be brought into the asset pricing method, the attractiveness of the stock investment will be significantly reduced.

\subsection{Portfolios}

According to Markowitz's portfolio theory, by taking all possible sets of weights to merge two members $l_{1}$ and $l_{2}$, the outcome in general can be a curve bending to the left like the one presented in Figure 1, and the status composed based on current value weights is more likely to be $q_{1}$ or $q_{2}$, and less likely to be the minimum-risk portfolio $g$ on the curve. Once the number of participants gradually increases, the outcome can soon become a closed efficient set like the one presented in Figure 2. After introducing an opportunity cost or target $r_{f}$, the market portfolio or the optimal allocation of resource $m$, can be solved by maximizing the Sharpe ratio or slope. However, as soon as certain constraints exist on resource allocation, the original efficient set will shrink in most cases, and only a second best solution $m^{\prime}$ can be achieved. Nonetheless, as long as the condition of significant risk diversification can be fulfilled, either $g$ or $g^{\prime}$ on its own efficient frontier can still be deemed as the system factor for either efficient set, with or without constraints.

As to both of the different definitions of environment just mentioned, they are not unrelated at all. For example, if the whole environment at present cannot pursue effectively any better development opportunity on the return dimension, an effort to reduce systematic risk can still be the alternative. This is because, based on Markowitz's portfolio theory, reducing $\sigma$ while keeping $E$ unchanged can always reach a similar outcome of performance by raising $E$ while keeping $\sigma$ unchanged. Moreover, since systematic risk can still be effectively reduced by allying a heterogeneous partner, it is therefore necessary for even developed nations to build dependable economic relationships with developing nations. 


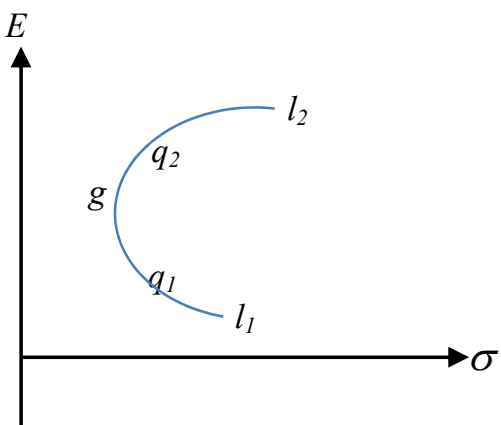

Figure 1. Compositions from two members

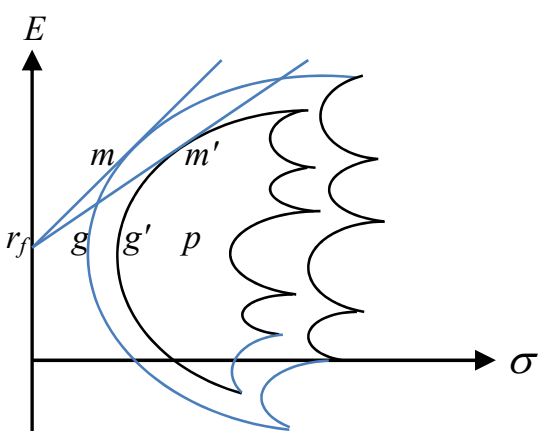

Figure 2. Market portfolio with or without constraints

\subsection{Basis for Performance Evaluation}

Although the appraisal basis of performance in the ' $\sigma-E$ ' environment can be WINDEX, it is still not by itself sufficient to meet the requirement of objectivity. For example, in Figure 2, the optimal allocation portfolio with constraints is $m^{\prime}$, its deviation from the current status $p$ has a WINDEX difference of $W_{m^{\prime}}-W_{p}$, representing the maximum room of improvement within the constrained environment. Therefore, if the environment already can itself provide more opportunities to develop but has not been largely grasped, then, even if $W_{p}$ is improving, the conclusion still will be a negative performance. On the contrary, even if $W_{p}$ is deteriorating, so long as the difference of $W_{m^{\prime}}-W_{p}$ can be lowered, a positive performance of resisting stress will still be concluded.

\subsection{Path of Improvement}

Once again, based on Markowitz's portfolio theory, a curve like the one presented in Figure 1 can be similarly composed by both portfolios $p$ and $m^{\prime}$. On this curve, two different stages can be further identified to have different implications in economic improvement. In the first, similar to that from $l_{1}$ to $g$ in Figure 1 , it can be called the "path with absolute improvement", which can raise $E$ and reduce $\sigma$ at the same time; in the second, similar to that from $g$ to $l_{2}$ in Figure 1, it can be called the "path with relative improvement", which simultaneously raises $E$ and $\sigma$. Cleary, the former is important in both economic and political implications, and a company, or a nation, can still search for a new path of absolute improvement after reaching a turning point like $g$ in Figure 1 in the first stage.

For the job of solving the optimal allocation of resources, the EXCEL 'Solver', which stands for the programming solution, can be applied even under a number of constraints on resource allocation. These kinds of constraints can be easily confronted when only small adjustments on resource reallocation should be exercised to avoid a more severe strike on employment and social stability.

\subsection{Industrial Structure}

The industrial structure can now be discussed based on eq. (6). First of all, for a new company planning to join an industry, those three coefficients in this equation can directly provide important information about the environment. If the coefficient with the environment variable is relatively larger, then this must mean that the whole industry is still at the growing stage, and the company can operate with relative easiness even by riding with the tide. On the contrary, self-effort will become a more important element for success. At this time, if the coefficient with other related products has a negative sign, then the whole industry must be filled with competitive pressure. Unless confidence of making a dominant performance can be assured, otherwise, it may not be wise to become a newcomer.

If only one monopolist exits, then both the system variable and the one representing possible impact caused by all other related companies, will be missing in eq. (6), and market stability must rely on the sincerity of the monopolist. 
Once a new competitor appears, those missing variables should reappear. However, since the environment variable is still not the system factor of the whole industry, the sum of all three coefficients in eq. (6) will not be forced to equal 1 , and this certainly means that market stability still cannot reach its optimal condition. In the meantime, if $\beta_{2}$ is positive, then no competition pressure exists in the market, therefore the intention of putting together a cartel can be doubted.

By gradually adding competitors, the system factor of the industry will eventually be generated. At this moment, market stability cannot be further contributed to by any newcomer, and a competitive market can thus be defined.

\subsection{Social Welfare}

Traditionally, issues of maximizing social welfare can only be discussed under the condition of perfect competition. Leaving aside the question of how to define social welfare, based on eq. (6), when perfect competition must mean a negative $\beta_{2}$ which, in turn, represents only negative interference instead of corporation, to say that this is the premise for maximizing social welfare is hardly convincing. Moreover, once the industry cannot obtain any further improvement of risk diversification, not to mention growth rate, by adding any newcomer, doubts of misallocation of resources cannot be avoided.

In addition, in Figure 2, the optimal portfolio $m$ or $m^{\prime}$ is quite away from the minimum-risk portfolio of $g$ or $g^{\prime}$, respectively. When only 15 to 20 participants with not too different sizes can already compose a system factor like $g$ or $g^{\prime}$ (Fama, 1976), the number of participants in $m$ or $m^{\prime}$ must be even smaller. Therefore, when perfect competition must mean an industrial structure nearby to $g$ or $g^{\prime}$, its deviation from $m$ or $m^{\prime}$ is much larger.

The statement of not having too many participants in the optimal portfolio also explains that no country can take all industries. Moreover, even the so-called sunset industries can have their chance to regain their strength in the future. Not to mention that the whole nation's economy may become less stabilized without them. Therefore, the feasible set with constraints demonstrated in Figure 2 should be the normal object for analyses. To adopt a development strategy by completely emphasizing that the property of comparative advantage may overlook the values of stabilizing a society in the short run, and helping economic development in the long run, that can be contributed to by imposing necessary constraints upon resource allocation.

\section{Different Perspective of Market Equilibrium}

In the mainstream economic textbooks, the root of an economic problem has long been stressed to be scarcity. However, the current facts show that people are excessively wasting the world's limited resources. Moreover, financial markets have long been emphasized as being very important, but the facts also show that we cannot control these beasts. Furthermore, both problems are probably caused by neglecting the important relevance of the environment and system factors as necessary constraints on economic development.

\subsection{The Pricing View of Equilibrium}

First, for the monopolist, since only variable $\widetilde{R}_{i}$ remains in eq. (6), market equilibrium will hardly exist. This is because the coefficient of $\widetilde{R}_{i}$ can usually be far greater than 1 and can be easily manipulated by the monopolist, hence it can augment instability. Moreover, since no other competitor exists, there will be no other chance to obtain a better risk diversification, and even a better portfolio of resource allocation for the whole industry. Next, when the case of oligopoly is brought into discussion, if the system factor in eq. (6) is replaced by an environment factor which, in turn, has yet to reach a level of significant risk diversification, then, since there is still some room for further risk diversification, no issue of market equilibrium can be justifiably analyzed. Finally, as has been well explained in section 4.3, even if the system factor can be produced in the industry under sufficient competition, the result will still differ greatly with the optimal portfolio of resource allocation.

In addition, the other main function of the system factor is to associate with the market to construct a pricing mechanism with the best stabilization this market can achieve, as can be clearly demonstrated by eq. (5) or (6). However, since the whole job of analysis is only undertaken within an industry, it is believed that, at most, only a partial equilibrium result can be obtained under this situation. Once the required system factor can be created for every industry and the whole nation, the general equilibrium result can be discussed. However, a still better consideration is to obtain a general equilibrium result with respect to all sectors, including the economic one in order 
to pursue the goal of national sustainment.

\subsection{The Market Clearing View of Equilibrium}

According to Markowitz's portfolio theory, in a ' $\sigma-E$ ' environment, as long as both system factors for either the supply or demand side of the market can be different, no intersect of supply and demand curves can be automatically obtained. The deviation must be caused by different motivations and ethics residing in either side. Only if either side can be forced to twist its curve can a compromised price and quantity be resulted in the market. Usually, the supply side has a better capability to dominate the market, and the phenomenon of bullying consumers can frequently occur. (Note 2)

After Smith a great number of economic scholars believed that an individual ideology is difficult to observe but not the collective one; and also believed that if people can conduct their economic behavior based on selfishness, then, in the end, the market can automatically create a mixture and generate altruism as well as equilibrium. (Note 3) This is because Smith had already identified the difference between systematic and individual components. (Note 4) However, the market is itself full of uncertainty, (Note 5) and this, in turn, will make equilibrium difficult to reach. (Note 6) This is because, by definition, whenever either the supply or the demand side can still reveal its own individual components, no intersection or market equilibrium can be automatically reached. In other words, even if the system factors can be generated for both sides of supply and demand, so long as they are not homogeneous, still no market equilibrium can be automatically achieved, and only compromised prices and quantities can be realized in the market.

\subsection{The Sustainment View of Equilibrium}

On the subject of the basic missions of a nation, that can include the protection of the right to live for every citizen, and the pursuit of the eternal goal of national sustainment. Clearly, all economic activities consume resources to satisfy these two possibly conflicting missions. However, without a long-term goal that can guide personal consumption behavior, people will easily become myopic and ignore their long term responsibility. The human race is never more than one generation away from extinction. Therefore, even personal consumption should not infringe a nation's sustainability.

The problem is, the way to correct personal consumption behavior can only be progressive, and had better be practiced through a national system of education, or even under a global competition mechanism of national pride. This is because personal consumption behavior is much easier for fine tuning with a proactive attitude. The improvement indicator of economic life introduced in $\mathrm{Yu}$ (2013b) should be one of the possible suggestions under this concern. (Note 7)

Clearly, the economy is only one single sector under the goal of national sustainment. Therefore, all economic externalities should have long been internalized. After that, based on Markowitz's portfolio theory, the true optimal allocation of resources that can include all economic and non-economic sectors and conform to the goal of national sustainment can be searched. However, this kind of undertaking may contradict with the spirit of a free market, but it is always necessary since realization of a free market has to rely on the interactions with other non-economic sectors. (Note 8) Moreover, when the performance of a free economy can be either right or wrong, there must be a long-term goal serving as a guide to protect the right of future generations and ensure the capability of maintaining national sustainment. (Note 9)

\section{Different Stages of Economic Development}

Generally speaking, eq. (5) or (6) in section 4 already indicates that the economic world should have its own sufficient strength of self-control. Under a similar logic, it can probably be tried if there is also a workable framework that can explain how economic development will naturally proceed, (Note 10) and the Chinese concept of the 'Five Elements' may be able to provide a clue. (Note 11)

Basically, the components of the Five Elements are Metal, Wood, Water, Fire and Earth, and its evolution can be shown to have two different types of cycle. In the generating cycle, Fire generates Earth, Earth generates Metal, Metal generates Water, Water generates Wood, Wood generates Fire, and the cycle repeats. In the overcoming cycle, Fire overcomes Metal, Metal overcomes Wood, Wood overcomes Earth, Earth overcomes Water, Water overcomes Fire, and the cycle repeats.

Since the dominant force driving our economic world always comes from human willingness and ability, therefore, the progress of the Five Elements must rely totally on human wisdom, (Note 12) and the main incentive through the whole generating cycle is to avoid economic failures. At the very beginning, the primitive economy could be deemed 
as the Fire stage, and humans were collecting subsistence items for living. After recognizing the risk of famine and the tamable possibility of certain items, economic development moved into the pastoral economy, or the Earth stage, to provide our ancestors partial control of their living environment.

Once the problem of too much surplus emerged, human wisdom was exercised to effectively utilize those surpluses and avoid failure. As a consequence, companies gradually emerged and became the basic units to practice professional specialization. In the end, the economy moved into the Metal stage and was called the manufacturing economy. At this time, people were already satisfied with substance items, and this automatically raised their need for necessities. After the economy of scale could generate sufficient surplus, turning to globalization to reduce costs and expand markets became necessary, and the economy moved into the Water stage, representing both logistic and financial economies, and the expansion of infrastructures and financial credits speeded up. Once reaching its maturity, the pressure of competition forced suppliers to exercise their wisdom in order to better understand and keep their customers, or even to try speculation opportunities in the financial market. At this point in time, necessities were saturated and luxuries became popular. The importance of consumer information and innovation knowledge gradually increased, the Wood stage, or the so-called knowledge economy emerged. (Note 13)

At present, garbage and ecological problems have gradually caused a serious threat to public safety. In order to conform to the eternal goal of Earth's sustainment, human wisdom is now required to reconsider how to more effectively use scarce resources with better ethics. It is therefore a natural move into the next stage, Fire, to restart a new cycle. Not only new forms of seeds and energy will be created or found to support new styles of production, but also new patterns of consumption behavior will emerge to meet the challenge of better ethics.

There is also a possibility of making a jumping move towards developing a nation's economy, if the conditions of the world economic development and the internal conditions of national comparative advantages in factor endowment can be matched. For example, since the world has already moved into the Wood stage, therefore, if one nation has sufficient human resources to meet the world's needs, it can certainly jump to its own Wood stage to develop its economy. India should be the best sample under this category. However, since it is not a homeopathic development, the intentionally excessive development of the Wood Element may overcome significantly the development of the Earth Element. This is because, in general, people will see agricultural or pastoral jobs as inferior choices, especially when they require excessive labor whilst providing mostly unattractive incomes. As a consequence, in the future, when compared to other nations, problems of food shortage may occur much more frequently. Certainly, a possible solution can still be looked for by forming an alliance with another nation that can be complementary in economic development.

\section{Conclusion}

Although human beings economic needs can be much more complex than that of other animals on this planet, however, the priority concern should still be the same one of surviving. Since the way to stay alive can include all economic activities of satisfying immediate and future needs, confronting uncertainty and risk is thus unavoidable. Which means, other than scarcity, another major reason that can cause economic problems should be risk. So far, the greatest innovation to control risk throughout society is the time deposit, and fortunately it stops there. Eventually, having uncertainty without risk can only cause surprise; not to mention that no failure equals no economic problem.

Contrasting to a one-dimensional return world, the analytical method in a two-dimensional risk and return world must be very different. So far, the best tool for the latter is still the Markowitz's portfolio theory. On the one hand, its concept of risk diversification states that, even after achieving a level of significant risk diversification, there can still be a systematic component that is undiversifiable; on the other hand, its technique of programming solution can be applied to find out the optimal portfolio of resource allocation or the minimum-risk portfolio. While both portfolios can exactly represent two different kinds of environment, the old problem of being unable to quantify environment factors can now have a preliminary solution.

As a matter of fact, the traditional view of economic equilibrium is actually a misunderstanding. This is because, once the analytical environment needs to be expanded from a one-dimensional return into a two-dimensional risk and return world, the importance and necessity of having a traditional economic equilibrium can be largely reduced. At present, and especially in terms of willingness, both sides of supply and demand cannot coincide perfectly with each other, and this certainly means that no perfect equilibrium can automatically exist. According to Markowitz's portfolio theory, as long as the number of participants from either the supply or the demand side can be sufficient, a significant level of risk diversification can be automatically achieved. However, in order to generate market equilibrium, both ability and willingness from either side are required to have a perfect match. This certainly means that the system factor from either side must be exactly the same. Unfortunately, at present, this still is an expectation when both sides do not have the same set of values and ethics. 
In addition, perfect competition can only be defined as to being located nearby the minimum-risk instead of the optimal portfolio of the environment. When both portfolios are far apart from each other, the belief that perfect competition can conform to the principle of maximizing social welfare should be doubtful, especially when adding more newcomers that not only cannot contribute anymore to the whole environment, but also will raise the concern of resource misallocation.

Nonetheless, once increased competition can already generate a system factor, the whole market can be deemed as to have already reached the most stabilized condition, and issues of partial equilibrium can still be reasonably discussed under these circumstances, but with different implications. After the system factor can be generated for every industry and the whole nation, issues of general equilibrium can be studied but, again, with different implications. However, the best effort should always be exerted to study issues of general equilibrium within an environment that includes all economic and non-economic sectors in order to achieve the goal of national sustainment.

The importance of the environment, or even the system factor, has long been excessively overlooked. For example, for one globalized and one localized company their business risks must be largely different. It is therefore necessary to put them into different categories of industry, otherwise unfair competition would occur between them. As another example, once the system factor can be internalized in an analytical model, it will let the model possess a very strong power of balancing, such that the weights of all controllable or uncontrollable forces of influence will be required to equal one. Clearly, this just reflects common sense, and also highlights a fact that the economic world should have its own strength of self-control, as it would become chaotic only if the system factor is excluded from economic analyses.

Once the importance of system factor can be recognized, a reasonable goal must be set in place. Under the economic view, this goal can only be the sustainment of the environment. For individuals only having limited life, without setting a long-term goal as the guide, their behavior of consumption may very often be out of control, and hence can infringe the right of future generations. To study economic equilibrium under this circumstance may be too myopic and not very meaningful. A nation is supposed to live forever. Therefore, the present everyday consumption should never be able to damage national sustainability in the future.

If the importance of system factor can receive more attention, then a greater number of economic issues can be accordingly discussed. For example, in trade negotiations if all participants would only quote their own mutually exclusive ethics in talks, no intersection can be possibly delivered. As another example, while dealing with risk management in the financial market especially about extremities, and if the cause came from the system factor, then the main effort should focus exactly on reducing the systematic risk by any and all means. While predominantly based on Markowitz's portfolio theory, risk diversification, with the help of another market or other markets, must be considered. As a final example, if an environment or a system factor can be included in the framework of economic analysis, then the traditional assumption of all other things being equal may have a chance to be released on some occasions.

After receiving a significant amount of criticism, economics must reinvent itself in order to conform to the following declaration, that is, "just as biology became a true science in the twentieth century, so too will economics come into its own as a science in the twenty-first century." (Beinhocker, 2007, p.ix) In the end, economics shall be no more a dismal science claimed by Thomas Carlyle; as it also can correct the following view which states that economists may be the only ones who believe that a perfect condition will exist in the future (Sedlacek, 2011, p.22, Note\#25), because the analytical approach in a perfect state is already there.

\section{References}

Arutyunov, A. V., S. E. Zhujovskiy, \& N. G. Pavlova. (2013). Equilibrium price as a coincidence point of two mappings. Computational Mathematics and Mathematical Physics, 53(2), 158-169. http://dx.doi.org/10.1134/S0965542513020048

Becker, G. S. (1975). Human Capital: A Theoretical and Empirical Analysis, with Special Reference to Education ( $2^{\text {nd }}$ ed.). New York: Columbia University Press.

Beinhocker, E. D. (2007). The Origin of Wealth. Mass.: Harvard Business School Press.

Block, F. (2004). Postindustrial Possibilities: A Critique of Economic Discourse, (in Chinese). Newpei, Taiwan: Socio Publishing.

Cheng, Y. (2002). The WINDEX View of Stock Investment, (in Chinese). Master thesis of Department of Economics, Ming-Chuang University, Taiwan, ROC.

De Vroey, M. (2006). The temporary equilibrium method: Hicks against Hicks. The European Journal of the History 
of Economic Thought, 13(2), 259-278. http://dx.doi.org/10.1080/09672560600708318

Fama, E. F. (1976). Foundations of Finance. New York: Basic.

Holcombe, R. G. (2008). Advancing economic analysis beyond the equilibrium framework. Review of Austrian Economics, 21(4), 225-249. http://dx.doi.org/10.1007/s11138-008-0043-7

Israelsen, C. (2005). A refinement to the Sharpe ratio and information ratio. Journal of Asset Management, 5(6), 423-427. http://dx.doi.org/10.1057/palgrave.jam.2240158

Lang, D., \& M. Setterfield. (2006-7). History versus equilibrium? On the possibility and realist basis of a general critique of traditional equilibrium analysis. Journal of Post Keynesian Economics, 29(2), 191-209.

Limpert, E., W. A. Stahel, \& M. Abbt. (2001). Log-normal distribution across the sciences: Keys and clues. Bioscience, 51(5), 341-352. http://dx.doi.org/10.1641/0006-3568(2001)051[0341:LNDATS]2.0.CO;2

Loasby, B. J. (1991). Equilibrium and Evolution: An Exploration of Connecting Principles in Economics. Menchester, UK: Menchester University Press.

Markowitz, H. (1959). Portfolio Selection. New Haven: Yale University Press.

Myers, M. L. (1976). Adam Smith's concept of equilibrium. Journal of Economic Issues, 10(3), 560-575.

Robinson, J. (2000). History versus equilibrium. In D. A. Walker (Ed.), Equilibrium: Introduction to Equilibrium in Economics (pp160-171). Cheltenham. UK: E. Elgar.

Sedlacek, T. (2013). Economics of Good and Evil: The Quest for Economic Meaning from Gilgamesh to Wall Street, (in Chinese). New-Pei, Taiwan: Streamer.

Sharpe, W. F. (1994). The Sharpe ratio. Journal of Portfolio Management, 21(1), 49-58. http://dx.doi.org/10.3905/jpm.1994.409501

Smith, A. (1776). The Wealth of Nations, edited by E. Cannan (1976). Chicago: University of Chicago Press.

Smith, A. (2000). The Theory of Moral Sentiments. New York: Prometheus.

van den Berg, R., \& G. Dhesi. (2004). The equilibrium is never perfect: The dynamic analysis of C.-F.-J. d'Auxiron. History of Political Economy, 36(1), 1-29. http://dx.doi.org/10.1215/00182702-36-1-1

Yu, Y. (2012). The asset pricing system. Modern Economy, 3(5), 473-480. http://dx.doi.org/10.4236/me.2012.35062

Yu, Y. (2013a). A more practical method for explaining supply. Research in World Economy, 4(1), 76-81.

Yu, Y. (2013b). A more practical method for explaining demand. Research in World Economy, 4(2), 18-27.

\section{Notes}

Note 1. If different financial assets can be related with high stability, then, as long as the time condition can also be matched, arbitrage opportunities can be easily created.

Note 2. Although it is still possible for consumers to acquire a good deal, however, this should only happen rarely if luxuries can be excluded.

Note 3. Smith believed that the key factor is sympathy. "One version of the idea of equilibrium was employed in Smith's moral philosophy in explaining how moral faculties are brought into balance through the principle of sympathy.”(Myers, 1976, p.561)

Note 4. For example, "these general features are always more striking and remarkable than any violation which it may undergo in particular cases. Thus anger is an emotion of a particular kind; and, accordingly, its general features are always more distinguishable than all the variations it undergoes in particular cases." (Smith, 2000, p.477) It is interesting to know that this root can still be traced one step earlier. "Auxiron describes the order of the market as a "moral equilibrium", ...that there is at work in the economy an automatic mechanism that tends to establish "moral equilibrium"." (van den Berg and Gurjeet, 2004, p.8)

Note 5. "Smith's concept of equilibrium, as we will see, also contains an element of uncertainty." (Myers, 1976, p.564)

Note 6. "As soon as the uncertainty of the expectations that guide economic behavior is admitted, equilibrium drops out of the argument and history takes its place." (Robinson, 2000, p.160) Also, "equilibrium analysis is generally ill-suited for representing a future subject to fundamental uncertainty." (Lang and Setterfield, 2006-7, p.191); "Equilibrium models cannot be salvaged by adding stochastic elements to them, because the nondeterministic components of economic progress are not stochastic or random." (Holcombe, 2008, p.237) 
Note 7. More suggestions can include, for example, the 'positional goods' introduced by Block (2004, p.268), which are something that can become even more when more are consumed.

Note 8 . In a very early time Karl Polanyi already moved all other non-economic environment factors onto the front stage and treated them as the keys to effective operation of capitalism (Block, 2004, p.104).

Note 9. "The idea of evolution was not itself new and was indeed familiar in the context of movement towards a particular goal." (Loasby, 1991, p.13)

Note 10. As Beinhocker (2007, p.13) once stated, "the economy is truly an evolutionary system, and there are general laws of evolutionary systems, then it follows that there are general laws of economic."

Note 11. Smith (1976, p.405) once pointed out a similar statement that "[a]ccording to the natural course of things, therefore, the greater part of the capital of every growing society is, first, directed to agriculture, afterwards to manufactures, and last of all to foreign commerce."

Note 12. A similar view can also be found in Becker (1975).

Note 13. The whole process of evolution can certainly answer a question raised by Beinhocker (2007, p.11), that is, "Why has the growth in wealth and complexity been sudden and explosive rather than smooth?"

\section{[Appendix I] Proving that the sum of all three coefficients must equal 1}

For a regression model having three explanatory variables $X_{1}, X_{2}$ and $X_{3}$, the process of standardization can

make $y=Y-\bar{Y}, x_{1}=X_{1}-\bar{X}_{1}, x_{2}=X_{2}-\bar{X}_{2}$ and $x_{3}=X_{3}-\bar{X}_{3}$, and all corresponding estimators for all

three coefficients can be listed as $\hat{\beta}_{1}=\left|A_{1}\right| /|A|, \quad \hat{\beta}_{2}=\left|A_{2}\right| /|A|$ and $\hat{\beta}_{3}=\left|A_{3}\right| /|A|$, in which,

$$
\begin{aligned}
|A| & =\sum x_{1}^{2} \sum x_{2}^{2} \sum x_{3}^{2}+2 \sum x_{1} x_{2} \sum x_{1} x_{3} \sum x_{2} x_{3} \\
& -\sum x_{1}^{2}\left(\sum x_{2} x_{3}\right)^{2}-\sum x_{2}^{2}\left(\sum x_{1} x_{3}\right)^{2}-\sum x_{3}^{2}\left(\sum x_{1} x_{2}\right)^{2} \\
\left|A_{1}\right|= & \sum x_{1} y\left[\sum x_{2}^{2} \sum x_{3}^{2}-\left(\sum x_{2} x_{3}\right)^{2}\right]+\sum x_{2} y\left(\sum x_{1} x_{3} \sum x_{2} x_{3}-\sum x_{3}^{2} \sum x_{1} x_{2}\right) \\
& +\sum x_{3} y\left(\sum x_{1} x_{2} \sum x_{2} x_{3}-\sum x_{2}^{2} \sum x_{1} x_{3}\right) \\
\left|A_{2}\right|= & \sum x_{2} y\left[\sum x_{1}^{2} \sum x_{3}^{2}-\left(\sum x_{1} x_{3}\right)^{2}\right]+\sum x_{1} y\left(\sum x_{1} x_{3} \sum x_{2} x_{3}-\sum x_{3}^{2} \sum x_{1} x_{2}\right) \\
+ & \sum x_{3} y\left(\sum x_{1} x_{2} \sum x_{1} x_{3}-\sum x_{1}^{2} \sum x_{2} x_{3}\right) \\
\left|A_{3}\right|= & \sum x_{3} y\left[\sum x_{1}^{2} \sum x_{2}^{2}-\left(\sum x_{1} x_{2}\right)^{2}\right]+\sum x_{1} y\left(\sum x_{1} x_{2} \sum x_{2} x_{3}-\sum x_{2}^{2} \sum x_{1} x_{3}\right) \\
& +\sum x_{2} y\left(\sum x_{1} x_{2} \sum x_{1} x_{3}-\sum x_{1}^{2} \sum x_{2} x_{3}\right)
\end{aligned}
$$

Assume $X_{1}$ is the system factor, then its covariance with every other variable will exactly equal to its variance, that

is $\sum x_{1} y=\sum x_{1} x_{2}=\sum x_{1} x_{3}=\sum x_{1}^{2}$, and all previous four equations can be simplified into

$$
\begin{aligned}
&|A|=\sum x_{1}^{2}\left[\sum x_{2}^{2} \sum x_{3}^{2}+2 \sum x_{1}^{2} \sum x_{2} x_{3}-\left(\sum x_{2} x_{3}\right)^{2}-\sum x_{2}^{2} \sum x_{1}^{2}-\sum x_{3}^{2} \sum x_{1}^{2}\right] \\
&\left|A_{1}\right|= \sum x_{1}^{2}\left[\sum x_{2}^{2} \sum x_{3}^{2}-\left(\sum x_{2} x_{3}\right)^{2}+\sum x_{2} y \sum x_{2} x_{3}-\sum x_{2} y \sum x_{3}^{2}\right. \\
&\left.+\sum x_{3} y \sum x_{2} x_{3}-\sum x_{3} y \sum x_{2}^{2}\right] \\
&\left|A_{2}\right|= \sum x_{1}^{2}\left(\sum x_{2} y \sum x_{3}^{2}-\sum x_{2} y \sum x_{1}^{2}+\sum x_{1}^{2} \sum x_{2} x_{3}-\sum x_{3}^{2} \sum x_{1}^{2}\right. \\
&\left.+\sum x_{3} y \sum x_{1}^{2}-\sum x_{3} y \sum x_{2} x_{3}\right) \\
&\left|A_{3}\right|= \sum x_{1}^{2}\left(\sum x_{3} y \sum x_{2}^{2}-\sum x_{3} y \sum x_{1}^{2}+\sum x_{1}^{2} \sum x_{2} x_{3}-\sum x_{2}^{2} \sum x_{1}^{2}\right. \\
&\left.+\sum x_{2} y \sum x_{1}^{2}-\sum x_{2} y \sum x_{2} x_{3}\right)
\end{aligned}
$$

The result can be shown to have $\left|A_{1}\right|+\left|A_{2}\right|+\left|A_{3}\right|=|A|$, which means $\hat{\beta}_{1}+\hat{\beta}_{2}+\hat{\beta}_{3}=1$. 